\title{
Reply to: Laparoscopic sleeve gastrectomy: a retrospective review of 1- and 2-year results. Surg Endosc 2010 (24):781-785
}

\author{
M. Proczko-Markuszewska • T. Stefaniak • \\ Ł. Kaska $\cdot$ Z. Śledzińnski • A. J. Lachiński
}

Published online: 19 August 2010

(C) The Author(s) 2010. This article is published with open access at Springerlink.com

We read with interest the article by Jacobs et al. [1] reviewing the experience of the Jackson Memorial Hospital in Miami, Florida, with laparoscopic sleeve gastrectomy. It is very encouraging to see that centres all around the world are able to present their retrospective material in Surgical Endoscopy. Nevertheless, there are some important issues that should be addressed in the context of this article.

First, the authors claim 82.5 and $83.4 \%$ eligibility to follow-up, though in fact the eligibility was only $66.4 \%$ (164 out of 247 operated patients). That percentage is much less valid for reasonable conclusions. There is no comment on possible reasons for such low follow-up adherence. Such a finding raises the question of whether the remaining patients decided to quit follow-up because they were dissatisfied with the results of surgery.

That brings us to another important issue, which is the conclusions of the authors. We believe that sleeve gastrectomy should not be considered as a universal therapeutic alternative for all patients. First, it has been previously presented by Wadden that any restrictive procedure demands adequate cooperation of the patient, especially in terms of motivation and psychological ability to follow rigorous postoperative dietary suggestions [2]. It has been presented that lack of such motivation can usually be attributed to inborn personality characteristics as well as skills that can be acquired during psychological seminars, workshops, and even psychotherapeutic meetings [3, 4]. It

M. Proczko-Markuszewska ( $\square)$. T. Stefaniak · Ł. Kaska • Z. Śledziński · A. J. Łachiński

Department of General, Endocrine and Transplant Surgery, Medical University of Gdańsk, Dębinki 7, 80-211 Gdańsk, Poland

e-mail: monika_markuszewska@op.pl has already been proven that lack of such preparation, its inadequate character or incorrect recognition of the patient's motivational capacities leads univocally to failure of bariatric therapy and in some cases even to serious complications [5-7]. Therefore, we strongly suggest psychological evaluation of patients and limiting sleeve gastrectomy only to those who are well motivated to follow dietary restrictions [8], unless sleeve gastrectomy is only planned as the first step of bariatric treatment. Some studies supporting this point of view have provided clear and strong evidence from series of laparoscopic gastric banding and vertical banded gastroplasty patients [9] that restrictive procedures must be augmented by efficient work by the patient. In our centre, patients who do not present adequate motivational capacities are qualified to gastric bypass, as sleeve gastrectomy almost always does not provide adequate long-term weight loss $[2,3,8]$.

Secondly, we should emphasise the fact that patients who suffer from gastroesophageal reflux disease and hiatal hernia should definitely not be qualified to sleeve gastrectomy, as this procedure increases the severity of the symptoms [10]. In this context, we always perform gastroscopy in preoperative preparation, and all patients with hiatal hernia or GERD are a priori qualified to gastric bypass [11]. Similar strategy is also employed by other authors [12].

Thirdly, patients with certain eating behaviours such as sweet-eating or binge-eating and who fail to lose them during psychological preparation are also known not to benefit from restrictive procedures such as sleeve gastrectomy or gastric banding [13]. Moreover, their unfavourable eating behaviours may lead to extension of the functional stomach and, in consequence, failure of the treatment [14]. In such cases, reoperation is often mandatory, gastric bypass usually being fashioned [9]. 
Finally, we would like to comment on the resolution of diabetes reported by the authors. We believe that such a high level of resolution must be associated more with diet maintenance and weight loss achieved by the patients than with any kind of hormonal change. It would be interesting to add information on the time from operation when such resolution was obtained. In gastric bypass patients, due to possible role of incretins [15], such resolution is immediate. To determine the character of the resolution observed by Jacobs et al., more information about the dynamics of the phenomenon should be provided.

In conclusion, we would strongly oppose the suggestion of Jacobs et al. that laparoscopic sleeve gastrectomy can be offered to any patient, especially if this operation is considered to be the final one. Adequate psychological motivational diagnosis, eating behaviours specificity, presence of GERD and hiatal hernia should always be evaluated and should add to the decision on the operation instituted in a particular patient.

Disclosures Authors Proczko-Markuszewska, Stefaniak, Kaska, Sledzinski, and Lachinski have no conflicts of interest or financial ties to disclose.

Open Access This article is distributed under the terms of the Creative Commons Attribution Noncommercial License which permits any noncommercial use, distribution, and reproduction in any medium, provided the original author(s) and source are credited.

\section{References}

1. Jacobs M, Bisland W, Gomez E, Plasencia G, Mederos R, Celaya C, Fogel R (2010) Laparoscopic sleeve gastrectomy: a retrospective review of 1- and 2-year results. Surg Endosc 24(4):781-785

2. Wadden TA, Sarwer DB (2006) Behavioral assessment of candidates for bariatric surgery: a patient-oriented approach. Surg Obes Rel Dis 2(2):171-179
3. Bradley C (2007) The value of ongoing psychological support for the bariatric patient, surgeon, and multidisciplinary team. Psychol Perspect. http://bariatrictimes.com. 02 June 2007

4. van Nunen AM, Wouters EJ, Vingerhoets AJ, Hox JJ, Geenen R (2007) The health-related quality of life of obese persons seeking or not seeking surgical or non-surgical treatment: a meta-analysis. Obes Surg 17(10):1357-1366

5. Renquist KE, Cullen JJ, Barnes D, Tang S, Doherty C, Mason EE, NBSR Contributors (1995) The effect of follow-up on reporting success for obesity surgery. Obes Surg 5:285-292

6. Stefaniak T, Babinska D, Trus M, Vingerhoets A (2007) The impact of history of sexual abuse on weight loss in gastric bypass patients. Psychosomatics 48(3):270-271

7. Makarewicz W, Kaska L, Kobiela J, Stefaniak T, Krajewski J, Stankiewicz M, Wujtewicz MA, Lachinski AJ, Sledzinski Z (2007) Wernicke's syndrome after sleeve gastrectomy. Obes Surg 17(5):704-706

8. Sarwer DB, Wadden TA, Fabricatore AN (2005) Psychosocial and behavioral aspects of bariatric surgery. Obes Res 13(4): 639-648

9. Weber M, Muller MK, Michel JM, Belal R, Horber F, Hauser R, Clavien PA (2003) Laparoscopic Roux-en-Y gastric by-pass, but nor rebanding, should be proposed as a rescue procedure for patients with failed laparoscopic gastric banding. Ann Surg 238:827-834

10. Braghetto I, Lanzarini E, Korn O, Valladares H, Molina JC, Henriquez A (2010) Manometric changes of lower esophageal sphincter after sleeve gastrectomy in obese patients. Obes Surg 20:357-362

11. Frezza EE, Ikrammudiri S, Gourash W, Rakitt T, Kingston A, Luketich J, Schauer P (2002) Symptomatic improvement in gastroesophageal reflux disease (GERD) following laparoscopic Roux-en-Y gastric by-pass. Surg Endosc 16(7):1027-1031

12. Madalosso C (2010) Gastric by-pass ammeliorates GERD symptoms in morbid obesity. Ann Surg 251(2):244-248

13. Fabricatore AN, Wadden TA, Sarwer DB et al (2006) Selfreported eating behaviors of extremely obese persons seeking bariatric surgery: a factor analytic approach. Surg Obes Rel Dis 2(2):146-152

14. Iannelli A, Dainese R, Th Piche, Facchiano E, Gugenheim J (2008) Laparoscopic sleeve gastrectomy for morbid obesity. World J Gastroenterol 14(6):821-827

15. Holst JJ, Gromada J (2004) Role of incretin hormones in the regulation of insulin secretion in diabetic and non-diabetic humans. Am J Physiol Endocrinol Metab 287:E199-E206 